\title{
Caminhos da formação: os desafios da supervisão de estágio no curso de Serviço Social de Miracema do Tocantins
}

\section{Paths of qualification: the challenges of apprenticeship supervision in the Social Work graduation course in Miracema do Tocantins}

\author{
Maria Helena Cariaga \\ Professora adjunta do curso de Serviço Social da Universidade Federal do Tocantins/Palmas, Brasil. \\ mhcariaga@gmail.com
}

\section{Maria José Antunes da Silva}

Professora assistente do curso de Serviço Social da Universidade Federal do Tocantins.

mariajose77@uft.edu.br

Resumo: Este texto tem por objetivo expor parte da experiência vivenciada na supervisão acadêmica de estágio no curso de Serviço Social da Universidade Federal do Tocantins, bem como refletir acerca dessa temática instigante que envolve diretamente os professores, os discentes e os supervisores de campo. O debate traz também os desafios que essa área da formação enfrenta no cotidiano, para sua realização diante da realidade no âmbito da particularidade, sem perder de vista a universalidade que envolve a temática.

Palavras-chave: Estágio. Supervisão em Serviço Social. Formação profissional.
Abstract: This article shows part of the experience in the academic apprenticeship supervision in the Social Work graduation course at Universidade Federal do Tocantins. Moreover, it reflects over this exciting theme that involves professors, students and professional field supervisors directly. The discussion also includes the challenges faced by this area of qualification daily, in order that such apprenticeship can be accomplished aiming at some particular reality without losing sight of the universality involving the theme.

Keywords: Apprenticeship. Supervision in Social Work. Professional qualification. 


\section{Introdução}

ste artigo visa expor parte da experiência vivenciada na supervisão
acadêmica de estágio como docente e também na coordenação do está-
gio no curso de Serviço Social da Universidade Federal do Tocantins, campus de Miracema. Realiza uma reflexão acerca dessa temática instigante que envolve diretamente os docentes, os discentes e os profissionais que atuam como supervisores de campo, a partir da análise do processo de trabalho vivenciado no período de 2010 a 2012.

Esse tema passou a ter predominância na formação a partir de determinado período nesse curso de Serviço Social, principalmente após 2010, momento em que a primeira turma do curso iniciou o estágio supervisionado curricular.

Para melhor compreensão do objeto em debate, vale destacar que o curso foi criado em 2007 e o estágio supervisionado inicia-se no quinto semestre e se finda no oitavo. É composto por quatro semestres de acordo com o Projeto Pedagógico do Curso (PPC 2010). Cabe ao estudante o cumprimento obrigatório de uma carga horária semestral de 105 horas, totalizando 420 horas em campos de estágio.

O referido curso está instalado em um dos sete $c a m p i^{1}$ da Universidade Federal do Tocantins, na cidade interiorana de Miracema do Tocantins, que está a uma distância de aproximadamente oitenta quilômetros de Palmas, a capital, onde há vários locais que se configuram como espaços sócio-ocupacionais para a realização do estágio.

Para melhor compreensão dessa experiência será necessária uma breve revisão histórica de como essa temática foi sendo discutida na profissão, bem como discorrer brevemente sobre o surgimento do Serviço Social, seu desenvolvimento, as aproximações teóricas das diversas matrizes teóricas metodológicas e as influências sofridas ao longo da construção da profissão.

Esta reflexão é destinada aos profissionais que atuam na área do Serviço Social. A intenção, aqui, é demonstrar as dificuldades e os desafios que essa

1. A Universidade Federal do Tocantins (UFT) é organizada a partir de uma estrutura em que conta com sete campi, localizados nas cidades de Araguaína, Arraias, Gurupi, Miracema do Tocantins, Palmas, Tocantinópolis e Porto Nacional. 
área da formação vivencia no cotidiano para sua realização diante da realidade, no âmbito da particularidade.

Partindo primeiramente de uma exposição do significado do estágio na formação dos profissionais e assim localizar o debate sobre a supervisão de estágio no Serviço Social contemporâneo, também é necessário situá-lo no âmbito dos processos macrossocietários e na perspectiva da totalidade.

\section{Apontamentos sobre a formação para o exercício profissional}

Nas duas últimas décadas do século XX, o Serviço Social no Brasil tem se fortalecido a partir de um acúmulo teórico-metodológico, potencializado pela produção acadêmico-científica, possibilitando a mobilização e a formação profissional em torno de um projeto ético-político profissional crítico.

Foi nesse sentido que houve intensa mobilização por parte dos profissionais para uma revisão curricular do curso de Serviço Social, com início em 1994 e aprovada em 1996. Tal revisão foi motivada pelas alterações sócio-ocupacionais e as exigências postas à profissão pela conjuntura contemporânea. A revisão curricular gerou as Diretrizes Gerais para o Curso de Serviço Social, cujo conteúdo estabelece que

os anos 1990 expressam profundas transformações nos processos de produção e reprodução da vida social, determinados pela reestruturação produtiva, pela reforma do Estado e pelas novas formas de enfrentamento da questão social, apontando inclusive para a alteração das relações entre o público e o privado alternando as demandas profissionais. (Abepss, 1999, p. 7)

As Diretrizes, além de anunciarem, também demarcam a base da formação e apontam os princípios definidos como aporte para a formação profissional. Dentre elas destacamos a flexibilidade nos currículos e uma dinâmica que proporcione o uso de várias técnicas para se atingir o conhecimento, como seminários temáticos, oficinas e atividades complementares. Há, sobretudo, a necessidade de rigor teórico, histórico e metodológico que propicie a compreensão dos desafios a serem enfrentados pelo profissional no universo da produção e reprodução da vida social. 
Conforme as diretrizes curriculares elaboradas pela Abepss, que direciona a formação profissional,

o estágio supervisionado é uma atividade curricular obrigatória que se configura a partir da inserção do aluno no espaço sócio-institucional, objetivando capacitá-lo para o exercício profissional, o que pressupõe supervisão sistemática. Esta supervisão será feita pelo professor supervisor e pelo profissional do campo, através da reflexão, acompanhamento e sistematização, com base em planos de estágio elaborados em conjunto pelas unidades de ensino e organizações que oferecem estágio. (Abepss, 1999, p. 18)

No entanto, vale lembrar, sobre o ensino da prática, que lugar de destaque ocupa essa formação e em quais princípios deve se apoiar. As Diretrizes apontam que o estágio supervisionado é uma atividade que privilegia a inserção do aluno no espaço socioinstitucional com o objetivo de capacitá-lo para o exercício profissional e pressupõe uma supervisão sistemática. Isto significa que a supervisão deve ser feita obrigatoriamente pelo professor supervisor e pelo profissional de campo, propiciando a reflexão, o acompanhamento e a sistematização com base em planos de estágio, elaborados em conjunto entre a unidade de ensino e a unidade do campo de estágio.

Segundo Guerra (2000), as dificuldades de ensinar a prática advêm da própria prática. Ou seja, pensar no ensino da prática na perspectiva de uma totalidade inserida em uma totalidade maior e com uma particularidade. Assim, faz-se necessário decifrar qual concepção embasa essa prática.

O ensino da prática possui mediações - entre elas, a investigação e as dimensões dos instrumentais técnico-operativos — que já se consolidaram com o exercício profissional. Mas não pode se limitar a isso é preciso ir além. Pensar no ensino da prática significa pensar no projeto de formação continuada para os profissionais que estão na supervisão de campo, o envolvimento dos docentes que compõem a formação desses profissionais, bem como o pleno envolvimento dos discentes em seu processo de aprendizado da prática profissional.

Nessa direção, o propósito de uma formação de estar comprometida com o desenvolvimento das competências que privilegie o domínio e a articulação das competências teórico-metodológica, ético-política e técnico-operativa. Isto 
significa uma apropriação da instrumentalidade do Serviço Social por parte dos profissionais, materializando-se como uma atividade racional e social, visando a transformação social.

É preciso destacar que, no que tange à formação profissional, os campos para realização de estágios se constituem importantes espaços para a reflexão. É preciso enfatizar também a relevância das bases teórico-metodológicas da profissão, que se constituem recursos essenciais para que o assistente social as acione no exercício de seu trabalho, pois "contribuem para iluminar a leitura da realidade e imprimir rumos à ação, ao mesmo tempo em que a moldam" (Iamamoto, 2003, p. 63).

Possibilita, também identificar a presença dos diferentes projetos que se antagonizam no cotidiano das instituições e as escolhas entre eles: o da instituição que oferece o espaço para a realização do estágio, o projeto da unidade de ensino e o projeto profissional dos assistentes sociais. Essas escolhas são orientadas para que se traduzam em atitudes práticas dos profissionais. Porém o ensino da prática não se resume à disciplina de estágio.

$\mathrm{O}$ fato de o estágio supervisionado ser considerado um momento singular e privilegiado para o aprendizado da prática profissional e, sobretudo, da construção dos valores éticos, não significa que seja o único, já que a prática profissional e especialmente a ética possuem uma relação orgânica com o cotidiano.

Outro ponto a ser destacado no sentido de propiciar uma eficácia da intervenção profissional se encontra na necessária transversalidade da pesquisa. Entendemos a investigação enquanto instrumento fundamental para o aprimoramento do processo de trabalho do assistente social. É a partir da investigação que se torna possível "fugir" da alienação cotidiana e da prática mimética e imediatista, propiciando buscar alternativas profissionais diante dos desafios colocados pelo contexto social, bem como desvelar a concreticidade das mudanças ocorridas no mundo do trabalho, na relação com o Estado e com a sociedade civil. Atualmente, nas políticas sociais, os profissionais são requisitados com frequência para realizar avaliações e estudos da realidade social.

Vale lembrar que não se trata de "qualquer modo de pesquisar". Isto porque nossa leitura da realidade que vai orientar nossas investigações depende da visão de mundo, de determinada maneira de conceber os sujeitos e a sociedade. Essa visão deve estar atrelada ao projeto ético-político para se direcionar as 
investigações e a interpretação dessa realidade social. Ao abordar a investigação é necessário enfatizar a questão metodológica, que possui relação intrínseca com o modo de pesquisar, ou seja, de ver, agir e pensar a realidade.

Nessa direção, o materialismo histórico-dialético tem sido a perspectiva teórico-metodológica que se configurou como hegemônica no Serviço Social.

Para essa perspectiva metodológica, segundo Lukács, "apenas o materialismo histórico pode desenterrar mentalmente esse fundamento da história e trazer à luz a infância da humanidade" (2011, p. 76). Sobretudo porque a realidade social exige do profissional um constante aprimoramento teórico-metodológico, capaz de apreender o movimento da realidade, histórico, contraditório, fornecendo categorias de análise da realidade, que permitem explicar a inserção da profissão no processo de trabalho. É também nas disciplinas de estágio que o acadêmico poderá desenvolver esse potencial criativo e investigativo.

O compromisso com a competência, que só pode ter como base o aperfeiçoamento intelectual do assistente social. Daí a ênfase numa formação acadêmica qualificada, fundada em concepções teórico-metodológicas críticas e sólidas, capazes de viabilizar uma análise concreta da realidade social — formação que deve abrir a via à preocupação com a (auto)formação permanente e estimular uma constante preocupação investigativa. (Netto, 2006, p. 155)

A citação acima aponta para a reflexão e a dimensão formativa do profissional de Serviço Social. Nesse enfoque, deve-se atentar para a importância da dimensão ético-política da competência profissional, atrelada às outras duas competências, a teórico-metodológica e a técnico-operativa. É a partir do desenvolvimento dessas competências profissionais que o assistente social poderá, em seu cotidiano de trabalho, buscar respostas, soluções e encaminhamentos para as demandas tradicionais e demandas emergentes da sociedade brasileira.

É mister destacar que a relação com os usuários dos serviços oferecidos pelas instituições onde atuam os assistentes sociais, como foi muito bem enfatizado por José Paulo Netto (2006), deve ter como componente elementar o compromisso com a qualidade da atenção destinada ao atendimento das demandas. É preciso salientar que, no que tange à formação profissional, os campos de estágio se constituem importantes espaços para a realização da reflexão 
sobre vários aspectos da formação e, principalmente, de como se dá o exercício profissional.

\section{Miracema do Tocantins e os desafios para o estágio supervisionado}

A supervisão se realiza como um processo histórico, desde a Grécia antiga, passando pela Idade Média, e logo sofre algumas mudanças na Idade Moderna. Essas mudanças se referem à capacitação do indivíduo. A história revela que o conceito de supervisão atende às técnicas predominantes do cenário social de cada época e de cada área profissional. Esse processo, no Brasil, buscou seu aprimoramento na literatura americana.

No Serviço Social, a supervisão inicialmente foi incorporada pelas ideias de Mary Richmond, ainda no século XX, que refletem a influência da psicanálise, visto que o supervisor assumia tarefas de terapeuta em relação ao supervisionado. Nesse sentido, Mary Richmond traçou uma nova metodologia de estudo e iniciou uma nova etapa da supervisão, na qual o supervisor era o orientador da metodologia.

No Brasil, a supervisão ocorreu a partir de 1936, ainda nas formulações das primeiras escolas de Serviço Social, sendo que o acervo da supervisão só foi organizado em 1947, tendo demorado aproximadamente quarenta anos. Contou com a inserção de três grandes autores: Helena Juracy Junqueira, Nadir Gouvêa Kfourie Balbina Ottoni Viera.

De maneira geral na América Latina, o autor Ezequiel Ander-Egg nos diz que a supervisão está amplamente relacionada a três disciplinas: a concepção que se tem do método do trabalho social, a pedagogia da supervisão e a interpretação das situações contextuais em que se realiza o trabalho desenvolvido no Serviço Social. Esse autor também ressalta que a supervisão poderia ser vista com dupla função: administrativa e didática.

Mas, retomando outros autores sobre esse tema, a contemporânea Alzira Lewgoy faz referência ao debate desse pesquisador, indicando "que o alcance atribuído pelo autor à supervisão era a prescrição no âmbito da eficácia e da eficiência, identificadas como dimensão de caráter tecnicista" (2009, p. 77). 
Já Marta Buriolla (2008) afirma que o exercício da supervisão requer conhecimentos especializados e experiência prática com fundamentos teórico-metodológicos, o que implica preparo profissional e reflexão sobre a prática, desenvolvendo, assim, habilidades técnicas, conceituais e sociais.

Retomando as palavras de Lewgoy (2009, p. 89),

não posso deixar de argumentar que a supervisão de estágio é uma instância na grade curricular que, ao realizar a interlocução entre a universidade e o mundo do trabalho, impõem aos acadêmicos, trabalhadores, professor-supervisor e assistentes sociais a tarefa de captar esse mundo da pseudoconcreticidade em que é envolvida a realidade educacional. As novas tecnologias, o processo de globalização, as novas requisições advindas do mercado, evidenciadas no exercício profissional, são relevantes para a análise e articulação de saberes e para a exequibilidade do processo de supervisão.

Nesse sentido, podemos compreender melhor quais são as bases teórico-metodológicas e técnico-operativas necessárias para ser desenvolvidas no desenrolar do processo de estágio e o acompanhamento da profissão que atualmente devem estar em evidência.

O curso de Serviço Social da Universidade Federal do Tocantins instalado no campus de Miracema do Tocantins, em sua política de estágio, contida no PPC de 2010, prevê que os alunos devem iniciar seu estágio no quinto período do curso e essa fase tem duração de quatro semestres subsequentes, finalizados no oitavo período, como já elencado. Essa é uma condição na formação dos discentes que tem levado a questionamentos sobre essa formação, o tempo de duração, as distâncias a ser percorridas e outras dificuldades enfrentadas.

A Universidade Federal do Tocantins possui sete campi, distribuídos por todo o estado. No ano de 2007, em sua expansão, foi criado o curso de Serviço Social na cidade de Miracema do Tocantins. Porém é importante observar que para a instalação desse curso eram necessárias determinadas condições que envolviam a existência de determinado número de espaços sócio-ocupacionais visando atender certo número de campos de estágio curricular.

Consideramos que esse foi um dos desafios enfrentados, ou seja, a falta de espaços institucionais para a oferta de vagas para o estágio e também a 
quantidade suficiente de assistentes sociais que podiam responder pela supervisão de campo.

Para melhor compreensão dessa dinâmica, vale observar que o estado do Tocantins é constituído por 139 municípios, dos quais 129 são considerados de pequeno porte, ou seja, com menos de 20 mil habitantes. Essa informação nos alerta para o fato de que dificilmente municípios com essas características possuem assistentes sociais em número suficiente para receber alunos para a realização do estágio, tendo em vista a normatização a ser seguida do conjunto CFESS/Cress, de n. 533/2008.

Convém considerar a particularidade da região e os aspectos locais ou, ainda, no âmbito regional, características que indicam que o poder público oferece o maior número de vagas para os estágios.

O cumprimento do estágio na formação dos alunos se dá a partir do quinto período, e esse momento envolve o aluno num processo de formação educativa que implica outras dimensões, como explica Lewgoy (2009, p. 31):

Ocorre que esse momento, em que o sujeito envolvido na formação e no processo educativo, "os alunos com as suas múltiplas e históricas necessidades, de ordem material, afetiva, política e ética, e quem, pela necessidade, e pelo desejo, poderá alterar de forma coletiva ao que está instituído".

Vale lembrar que a particularidade do estágio supervisionado no curso de Serviço Social de Miracema se constitui e se apresenta sob várias dimensões. Muitas dessas fogem ao âmbito docente e também ao das instituições envolvidas. Ou seja, essas dimensões são demarcadas pelas dificuldades e pelos obstáculos a ser enfrentados no cotidiano, principalmente por parte dos alunos. Muitos desses enfrentamentos perpassam pelo aspecto coletivo, em função da distância a ser percorrida da cidade de Miracema, onde fazem o curso, até o local do campo de estágio.

Desde que o estágio teve início, podemos constatar vários impasses para sua operacionalização, tendo em vista que a cidade é pequena e oferta poucos espaços para esse fim. Para isso foi necessário buscar vagas para o estágio em 
outras cidades vizinhas e em diferentes espaços sócio-ocupacionais, de maneira que foram envolvidas muitas outras instituições no âmbito governamental.

Conforme relatório elaborado pela coordenação sobre o estágio em 2012, aproximadamente $20 \%$ dos campos de estágio estão em Miracema e nas cidades mais próximas, sendo elas: Lajeado, Rio dos Bois, Miranorte, Fortaleza do Tabocão e Tocantínia. A cidade de Palmas, capital do estado, recebe os demais $80 \%$ dos alunos.

O campus de Miracema se encontra na região central do estado, onde funciona o curso de Serviço Social. Está a aproximadamente a um quilômetro do município de Tocantínia, com 6.736 habitantes, dividido pelo rio Tocantins. Há uma balsa que faz a ligação dos municípios. A outra forma de acesso entre essas cidades é um percurso de aproximadamente 40 quilômetros. Miracema está a 23 quilômetros de Miranorte, com 12.623 habitantes, a 46 quilômetros de Rio dos Bois, com 2.570 habitantes, a 25 quilômetros de Lajeado com 2.773 habitantes, e Fortaleza do Tabocão está a 70 quilômetros de Miracema, com 2.419 habitantes.

A população total desses municípios gira em torno de 47.805 habitantes. Todos oferecem vagas para estágio, e os alunos percorrem diversos caminhos para realizar essa atividade acadêmica. Muitas vezes o fazem por meio de transporte coletivo, interestadual e/ou de motocicleta. Essa é uma questão delicada, pois os alunos enfrentam a rodovia estadual, a TO-050, e a federal BR-153, quando vão para as cidades de Fortaleza do Tabocão e Rio dos Bois.

Conforme já citado, cerca de $80 \%$ dos alunos viajam para fazer o estágio na capital. Para chegar a Palmas, enfrentam a distância de oitenta quilômetros entre um município e outro. Além disso, fazem a travessia pelo rio Tocantins, a qual, até pouco tempo atrás, era feita de balsa — hoje existe a ponte —, o que resultava em aproximadamente duas horas de percurso.

Paralelamente a isso, os estagiários devem superar as distâncias dentro das cidades nas quais estão fazendo o estágio. No caso de Palmas, que possui uma extensão de quarenta quilômetros, as distâncias são significativas de um local para o outro, e as condições objetivas não favorecem a locomoção com facilidade, ou seja, há necessidade de se gastar mais tempo no uso do transporte coletivo para se chegar ao estágio. 
É preciso considerar que esses trajetos não são fáceis em uma capital como Palmas, que não possui meio de transporte coletivo eficiente. Muitas vezes, quando o aluno chega ao local do estágio, já está cansado, com fome e abatido pelo estresse no enfrentamento dessas e de outras dificuldades de seu cotidiano.

Lembramos que a criação do curso de Serviço Social da Universidade Federal do Tocantins ocorreu no interior do estado e que apesar de a capital ser próxima, ainda assim os estudantes precisam fazer um deslocamento que se configura, muitas vezes, como uma viagem, o que implica custos físicos e financeiros consideráveis.

Para melhor compreensão do perfil dos alunos da UFT, recorremos aos dados da pesquisa realizada pela Comissão Permanente de Avaliação (CPA) em 2010, na qual foi constatado que a renda dos alunos da Universidade Federal do Tocantins estava assim distribuída: 16,76\% viviam com uma renda familiar de até um salário mínimo; 40,68\%, com renda de um a três salários. Somando esses dois dados, observa-se que $57,45 \%$ têm renda de até três salários mínimos. Entre três e seis salários mínimos há $22,05 \%$, e somente $7,89 \%$ dos alunos têm renda familiar superior a nove salários mínimos.

Esses números demonstram que essa universidade tem, na sua maioria, alunos com renda baixa, o que requer investimentos na área de assistência estudantil para permanência na universidade. É notório que os alunos dessa faixa etária da sociedade têm dificuldades de acesso aos recursos necessários para construir e desenvolver uma boa formação profissional.

Para além das necessidades financeiras dos alunos, cabe à universidade assumir o ônus de que ela está longe de oferecer determinados serviços que podem garantir a permanência dos discentes em sua formação. Compreendemos que a política de interiorização da formação profissional tem um custo financeiro, razão pela qual não é possível comparações com outras universidades que possuem campus localizado em regiões metropolitanas.

Desde o governo Lula, a política de educação tem sido a de privilegiar a sua interiorização no Brasil, conforme declarou o então presidente da República ao defender que conseguiram levar diversas universidades federais para o interior do país, em um processo de expansão dos cursos superiores. É nesse contexto que foi criado o curso de Serviço Social em Miracema do Tocantins. 
Vale dizer que os custos, as dificuldades e os obstáculos enfrentados pelas universidades que estão no interior do país ainda não são levados em consideração. Isso em relação ao orçamento destinado aos campi que estão distantes das capitais. Muitos são os itens a ser elencados quando se trata da interiorização, principalmente sobre a fixação dos professores, apoio estudantil para moradia, transporte, alimentação, bem como o acesso ao lazer e às atividades culturais.

Diante dessa realidade, o percurso para a implementação de novos espaços de estágio deve seguir as recomendações da resolução CFESS n. 533/2008. No entanto, muitos profissionais ainda têm resistido a ofertar essa atividade privativa. Para tanto, apresentam vários argumentos, dentre os quais que essa não é uma atividade obrigatória, não é remunerada, e as suas condições e sobrecarga de trabalho não comportam a supervisão para esses alunos, dentre outras justificativas que, na maioria das situações, são justas. Porém a universidade fica em uma situação difícil para resolver os problemas de vaga de estágio.

Perante as dificuldades de abertura de campos de estágio, pode-se observar que os motivos são semelhantes àqueles colocados por Guerra e Braga (2009, p. 545): “[os] contratos temporários ou parciais, por tempo determinado ou por programas, redução da jornada de trabalho e de salário, o duplo vínculo e os baixos salários, o trabalho em regime de plantão, dentre outras condições".

Para ampliar as vagas de estágio para os alunos foram utilizadas diversas estratégias a fim de abrir novos espaços, entre as quais a interlocução e a aproximação com vários municípios, por meio de reuniões, encontros com prefeitos, com secretarias da Assistência Social ou responsável pela área da assistência social naquele município e responsáveis pela defensoria pública do município de Palmas. Acrescentamos a isso também a realização de cursos, seminários e debates sobre essa temática com assistentes sociais. Todas essas atividades foram realizadas para que se ampliassem os espaços sócio-ocupacionais de estágio curricular para os alunos.

Vale dizer que outra estratégia utilizada para atender a necessidade de inclusão dos alunos nos campos de estágio, no período de 2010/2 até 2012/1 foram realizadas 147 visitas institucionais pela coordenação de estágio em hospitais, nas secretarias municipais e estaduais e demais espaços ocupacio- 
nais com assistentes sociais que pudessem receber os alunos no período de estagio. Nesse sentido, houve empenho e investimento nessa ação, que resultaram na abertura de 96 novas vagas de estágio. Isso representa que de acordo com as demandas, há necessidade de diferentes maneiras para o enfrentamento dessas questões.

Outra situação concreta da realidade refere-se ao fato de que no estado do Tocantins existe a Fundação Universidade do Tocantins (Unitins), instituição pública estadual que, a partir de 2006, iniciou a oferta de ensino de Serviço Social na modalidade à distância em todo o Brasil. Esta atuação se deu por meio de polos instalados nos locais mais inusitados para tal condição. Em 2009 a Unitins foi descredenciada na oferta dessa modalidade de ensino para o Serviço Social, mas sua presença marcante representa, no período em análise, um grande volume de alunos em processo de formação, ou seja, que necessitam de estágio curricular.

Só para se ter uma ideia desse volume de alunos, um estudo realizado e publicado por Marilda Iamamoto (2007) informa que, apesar de o curso ter se iniciado em 2006, somente a Unitins já ofertava no ano de sua pesquisa 2.760 vagas, ou seja, com menos de dois anos de funcionamento. Essa universidade estava na disputa por campos de estágio, juntamente com os alunos do curso de Serviço Social da Universidade Federal do Tocantins (UFT). Essa realidade materializa-se no cotidiano da formação do Serviço Social e também dificulta a abertura dos campos de estágio.

Nesse estudo observou-se que os caminhos e descaminhos do processo de ensino/aprendizagem no estágio precisa ainda realizar amplos debates no sentido de superar tamanhos desafios. Para isso faz-se necessário recolocar o estágio na agenda da profissão e da formação profissional, como espaço privilegiado da formação dos assistentes sociais.

O cumprimento do estágio pelos alunos, apesar de sua relevância na formação, não apresenta as condições objetivas para a sua efetivação. Faz-se necessário que todas as instituições envolvidas coloquem em sua agenda de prioridades o estágio como parte da formação dos alunos, sobretudo porque a criação do curso de Serviço Social em Miracema merece uma reflexão profunda nesse sentido. 
É importante ressaltar que os assistentes sociais devem também priorizar essa atividade, ou seja, que todos os envolvidos nesse processo no âmbito da formação acadêmica elejam como prioridade o estágio supervisionado, para que este se configure um espaço favorável para o aprendizado do exercício profissional. É nesse momento de aprendizado que o acadêmico deverá exercitar seu potencial crítico, reflexivo, analítico, desenvolver habilidades, reconhecer questões relacionadas ao espaço sócio-ocupacional, trabalhar e compreender as dimensões teórico-metodológicas, técnico-operativas e ético-políticas de sua intervenção.

\section{Considerações finais}

Considerarmos aqui a importância do debate e das reflexões acerca da realização do estágio supervisionado como um momento privilegiado na formação do Serviço Social. Ou seja, a questão não se resume apenas à discussão, mas suscita um aprofundamento e a priorização sobre o tema, com ênfase da sua relevância na formação profissional de futuros assistentes sociais.

É preciso ir além dos muros da universidade e provocar uma aproximação com resultados efetivos entre a academia, os profissionais e os supervisores de campo das diversas instituições. Essa aproximação é necessária e importante para todos os sujeitos envolvidos, principalmente porque esses profissionais detêm um conhecimento da particularidade da realidade, e isso precisa ser valorizado por toda a sociedade.

No que se refere à supervisão e sua construção no processo de formação acadêmica, podemos afirmar que é no chão da prática e no cotidiano que se constrói essa possibilidade, tendo em vista que essa construção deverá ser sustentada pela tríade aluno, supervisor de campo e supervisor acadêmico. No entanto, essa relação só poderá se consolidar na medida em que os três sujeitos envolvidos possam compreender e desenvolver essa atitude (Lewgoy, 2009). No entanto, além dessa tríade existem outros elementos importantes que necessitam de fortalecimento para garantir o processo de formação.

Nesse sentido, é preciso também levar em conta as questões relativas às condições objetivas em que se opera o estágio. Como os alunos têm vivenciado 
essa particularidade é demarcado pelo fato de o curso ser em Miracema do Tocantins, no interior do estado, ou seja, a distância que existe entre as cidades onde são ofertadas as vagas para os alunos e esta cidade; além disto, são poucas as instituições e poucos os profissionais disponíveis para que essa atividade privativa do assistente social seja realizada.

O processo de supervisão de campo passa pelo cotidiano que se opera entre sujeitos, aluno e supervisor de campo, supervisor acadêmico, gestores das instituições, os cidadãos que são atendidos, entre outros, sobretudo porque é na prática que se constituirá o estágio supervisionado.

Vale ressaltar a necessidade de criação de núcleos de formação do trabalho profissional a ser assumido coletivamente por todos os professores e todas as disciplinas que compõem o curso de Serviço Social, de forma a contribuir para que o ensino da prática atravesse todo o período de formação dos discentes, como uma das alternativas de superação para as questões de âmbito teórico-metodológico.

Essa seria uma das maneiras de minimizar as dificuldades encontradas pelos docentes e discentes no momento do cumprimento do estágio curricular. Outro ponto seria o de mobilizar e propiciar encontros coletivos, com seminários e oficinas, criando aproximações entre o ensino acadêmico e os supervisores de campo.

Entretanto, a construção desses caminhos pressupõe longas horas dedicadas a esse trabalho, tanto pelos docentes quanto pelos discentes e supervisores de campo. Sobretudo porque são horas de dedicação que exigem envolvimento entre os sujeitos, pois é o debate em conjunto com os aportes teórico-metodológicos e a apropriação destes que irá contribuir para que o aluno possa desenvolver suas competências e habilidades, favorecendo uma atuação no campo de estágio mais criativa, autônoma e com maior densidade teórica.

Recebido em 17/8/2015 - Aprovado em 16/10/2015 


\section{Referências bibliográficas}

ASSOCIAÇÃO BRASILEIRA DE ENSINO E PESQUISA EM SERVIÇO SOCIAL (ABEPSS). Diretrizes gerais para o curso de Serviço Social. Associação Brasileira de Ensino e Pesquisa em Serviço social. Brasília: Abepss, 1999.

BURIOLLA, M. A. F. Supervisão em Serviço Social: o supervisor, sua relação e seus papéis. 4. ed. São Paulo: Cortez, 2008.

GUERRA, Y. O ensino da prática profissional no Serviço Social. Temporalis, Brasília, v. 1, n. 2, 2000.

; BRAGA, M. E. Supervisão em Serviço Social. In: CFESS/ABEPSS. Serviço Social: direitos sociais e competências profissionais. Brasília: CFESS/ABEPSS, 2009.

IAMAMOTO, M. V. O Serviço Social na contemporaneidade: trabalho e formação. 5. ed. São Paulo: Cortez, 2003.

. O Serviço Social em tempo de capital fetiche: capital financeiro, trabalho e questão social. São Paulo: Cortez, 2007.

LEWGOY, M. A. B. Supervisão de estágio em Serviço Social: desafios para a formação e exercício profissional. São Paulo: Cortez, 2009.

LUKÁCS, G. O romance histórico. Tradução Rubens Enderle. São Paulo: Boitempo, 2011.

NETTO, J. P. A construção do Projeto Ético-Político do Serviço Social. In: MOTA, A. E. et al. Serviço Social e Saúde: formação e trabalho profissional. São Paulo: Cortez/ Opas/OMS/Ministério da Saúde, 2006.

\section{Webgrafia}

Disponível em: $<$ http://portal.mec.gov.br/index.php?option=com_content\&view=article \&id=16099:lula-destaca-politica-de-interiorizacao-do-ensino-superior-e-profissional \& catid=212\&Itemid=86> . Acesso em: 19 mar. 2013. 